\title{
EDITORIAL
}

\section{Steps of fronts in chemical engineering: An overview of the publications of FCSE}

\author{
Xiaowen Zhu, Yaodong Huang (凶), Jing-Kang Wang \\ School of Chemical Engineering and Technology, Tianjin University, Tianjin 300350, China
}

(C) Higher Education Press and Springer-Verlag GmbH Germany, part of Springer Nature 2018

The fronts of a subject could be perceived from the publications of top journals. We investigated four top journals on chemical engineering: AlChE Journal, Chemical Engineering Science, Industrial \& Engineering Chemistry Research and Chemical Engineering Journal. Based on Web of Science, in the last five years, these four journals have published 21062 papers, including 590 highly cited papers and 31 "hot" papers among which only 7 are from Industrial \& Engineering Chemistry Research and all the others from Chemical Engineering Journal (data obtained on November 17, 2018). The traditional research "Pure and pseudo-pure fluid thermophysical property evaluation and the open-source thermophysical property library CoolProp" is the most cited paper published in 2014 [1]. Both highly cited and "hot" papers were published in 2017 on electrodes of supercapacitors [2]. But researches on environmental science and engineering have been paid most attention with 17 of 27 both highly cited and "hot" papers on this research area. The most cited and "hottest" paper is "Boron nitride-based materials for the removal of pollutants from aqueous solutions: A review" in 2018 [3].

Over the past decades, research and technologies advancement in chemical science and engineering in China has expanded in a lightning speed globally. To meet the growing needs of knowledge exchange and understanding of the underlying scientific principles, we launched in 2007 a new journal named Frontiers of Chemical Engineering in China with all papers translated from the Chinese journals. Original research articles or reviews have been published since 2009. The new name Frontiers of Chemical Science and Engineering (FCSE) has begun only since 2011 and FCSE became one of the Transactions of the Chinese Academy of Engineering (CAE) in 2014. From CAE, we have received many supports, both academic and financial. Especially in the latest three years, we have organized some important Special Issues and Topics.

For the keywords given by authors or Web of Science (Fig. 1), "Carbon, Acid, Oxide, Oil, Metal, Cell, Drug, Catalyst, $\mathrm{CO}_{2}, \mathrm{CO}$, Membrane, Hydrogen, Process, Crystal, Gas..." appear more frequently, indicating that "environment, sustainable, bio-, medical, and catalysis" are hot topics in FCSE.

\section{Environmental \& sustainable is indeed a hot topic}

Unlike the most of "hot" papers in Chemical Engineering Journal mainly on treating waste water, two Reviews on $\mathrm{CO}_{2}$ published in FCSE are the most cited papers. Prof. Gong has reviewed the utilization of carbon dioxide by catalytic reactions, focusing on recent developments in catalytic materials, novel reactors, and reaction mechanism for methanation of $\mathrm{CO}_{2}$ [4]. In 2015, Prof. Stevens contributed "Review of solvent based carbon-dioxide capture technologies" as a Cover Paper. This review updated the status of large scale integrated carbon capture and storage technologies using solvent absorption for $\mathrm{CO}_{2}$ capture and provided an insight into the development of new solvents, including advanced amine solvents, amino acid salts, carbonate systems, aqueous ammonia, immiscible liquids and ionic liquids. These proposed new solvents aim to reduce the overall cost of $\mathrm{CO}_{2}$ capture by improving the $\mathrm{CO}_{2}$

Received November 23, 2018; accepted November 23, 2018

E-mail: Huangyaodong@tju.edu.cn 

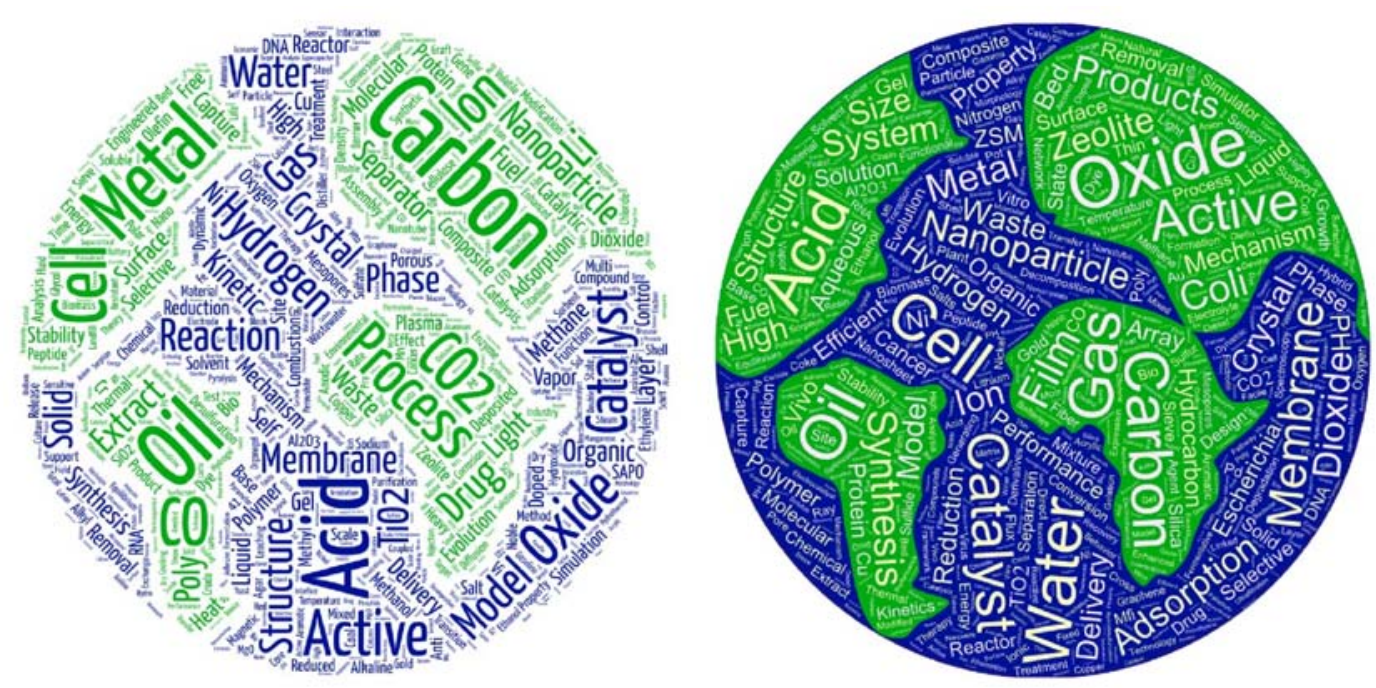

Fig. 1 Word cloud of the (left) Authors-Keywords and (right) Web of Science Keywords-Plus 2011-2018

absorption rate, $\mathrm{CO}_{2}$ capture capacity, thereby reducing equipment size and decreasing the energy required for solvent regeneration [5].

In 2016, we hosted "2016 Symposium on Frontiers of Chemical Science and Engineering - Environment and Sustainable Development" [6]. In this conference, we invited some of the speakers and relevant scientists contributing to the Special Topic on environment and sustainable development. Prof. John C. Crittenden et al. gave a Views \& Comments on the symposium [7]. Four groups made their contributions as Reviews and nine groups presented their latest research results in this Special Topic. Prof. Allen himself wrote the paper "Combining innovative science and policy to improve air quality in cities with refining and chemicals manufacturing: The case study of Houston, Texas USA" [8]. Allen figured out "Reducing emissions required innovative policy approaches. These coupled scientific and policy innovations are described, and the result, substantially cleaner air for Houston, is documented. The lessons learned from the Houston air quality experience are relevant to cities with similar population and industrial profiles around the world". The young scientist, Prof. Sun, gave a Research Article "Electrochemistry during efficient copper recovery from complex electronic waste using ammonia based solutions" [9]. This research proposes electrodeposition as the subsequent approach to effectively recover copper from the solutions after selective leaching of the electronic waste and focuses on recognizing the electrochemical features of copper recovery. Of course, there are some other papers which are good enough to be highlighted, e.g., those from Pontikes [10] and Lin [11]. But for the limited length of this editorial we suggest you read this Special Issue.

\section{Bio- and medical are the new trends}

Since our Editor-in-Chief, Prof. Jing-Kang Wang, is an expert in crystallization field, especially in medical area, we published many papers on "crystallization". In early 2013, Prof. Ulrich discussed important research developments and arising challenges in the field of industrial crystallization with an emphasis on recent problems. The most relevant areas of research have been identified. These are the prediction of phase diagrams, the prediction of effects of impurities and additives, the design of fluid dynamics, the process control with process analytical technologies tools, the polymorph and solvate screening, the stabilization of non-stable phases, and the product design [12]. There are about 10 papers published in that issue (Issue 1, 2013).

The crystallization and phase determination are the major bottle-neck problems in crystallography. Prof. Huang together with his postdoctoral co-advisor Prof. Szostak reviewed the synthesis and strategy of selenium-derivatized nucleic acids (SeNA) for nucleic acid crystallography. They suggest that SeNA may not only provide the rational strategies to solve the phase determination problem, but also offer a potential strategy to explore crystallization solutions [13]. This review is one of the papers from the special topic on "nucleic acid-protein chemical and structural biology for novel drug discovery" [14]. The guest-editor, Prof. Lilley's review is about "Ribozyme and the mechanisms that underlie RNA catalysis" [15]. The cover paper by Janez concluded that "DNA oligonucleotides containing four GGGGCC repeats exhibit folding into multiple G-quadruplex structures. Presence or absence of CC or TT residues 
at 5'- or 3'-ends of $d\left[\left(G_{4} C_{2}\right)_{3} G_{4}\right]$ sequence and composition of presumed loop residues were shown to have a profound effect on folding. Furthermore, complex equilibrium between different structures adopted by $\left[\left(\mathrm{G}_{4} \mathrm{C}_{2}\right)_{3} \mathrm{G}_{4}\right]$ could be influenced by $\mathrm{pH}$ and concentration of added $\mathrm{K}^{+}$ions" [16].

On March 10, 2017, Science launched a Special Issue on Synthetic Yeast Genome. Prof. Yuan of Tianjin University is the corresponding author of two papers [17,18]. In the same year, Prof. Yuan as one of the guest-editors organized a Special Issue on "Collaborations of China with the world in Synbio" [19]. Here we would like to mention six Chinese groups from which you could get a common sense of the main research group on Synbio in China. They are Prof. Yang's group of Shanghai Institutes for Biological Sciences [20], Prof. Zhou's group of Jiangnan University [21], Prof. Xiao's group of Tianjin University [22], Prof. Su's group of Beijing University of Chemical Technology [23], Prof. Dai's group of Tsinghua University before 2018 (now of Shenzhen Institutes of Advanced Technology, Chinese Academy of Sciences [24]) and Prof. Yu's group of Zhejiang University [25].

\section{Catalysis is always very important}

The third highly cited paper of FCSE is about "Recent advances in selective acetylene hydrogenation using palladium containing catalysts" by Prof. Anderson of University of Aberdeen in 2015 [26]. And two other Reviews also on catalysis with more than 30 citations are "Mesoporous zeolites as efficient catalysts for oil refining and natural gas conversion" in 2013 [27] and "A review on ex situ catalytic fast pyrolysis of biomass" in 2014 [28].

"Catalysis plays a central role during almost all of the transformation processes, such as oil refining, coal processing and utilization, fuel cell, energy storage, hydrogen generation and storage, solar energy utilization and biomass conversion. Catalysis also plays a very important role in environmental protection such as greenhouse gas emission, water purification, $\mathrm{CO}_{2}$ capturing and transformation." Thus, a Special Issue of FCSE on frontiers of catalysis chemistry and technology was organized by Profs. Liu and Li of Dalian Institute of Chemical Physics, CAS, China [29]. "These contributions covered a wide range of research topics focusing on novel process development and new catalyst and new methods for catalyst preparation, with applications to petro refinery, hydrorefining, olefins and/or PX production, biomass conversion, $\mathrm{H}_{2} \mathrm{O}_{2}$ production, $\mathrm{NO}$ reduction and $\mathrm{CO}_{2}$ separation/capture. This reflects the multidisciplinary feature of catalysis science and technology".

The Review "Engineering operando methodology: Understanding catalysis in time and space" contributed by Prof. Bañares of Instituto de Catálisis y Petroleoquímica [30] and the Research Article "Copper nanoparticles/polyanilinederived mesoporous carbon electrocatalysts for hydrazine oxidation" by Prof. Asefa of The State University of New Jersey in Issue 3, 2018 [31] are also worth reading.

\section{Processing is on the way of intelligent and saving energy}

Process systems engineering is not new but is on the way of intelligent and saving energy. Engineering organized a Special Issue on "Smart Process Manufacturing" in 2017. As the guest-editor, Prof. Qian said "The process industry, which mainly includes elementary raw material industries such as petroleum, chemical engineering, steel, nonferrous metal, and building materials $\cdots$ is at a critical and historic moment of transformation, resulting in the development of accurate production operations, efficient and smart manufacturing processes, and systemoptimized design with the integration of safety and environmental sustainability [32]." At the same time, he and his friend Prof. Gui published their research results in FCSE focusing on this area [33,34]. Based on the 20th Conference on Process Integration, Modelling and Optimization for Energy Saving and Pollution Reduction (PRES'17), in the last issue of FCSE in 2018, we will publish more than 15 papers coming from Czech, Germany, Italy, Hungary, France, Slovakia, Ukraine, Austria, and USA. These papers are mainly on sustainable energy utilization, integration and optimization.

Following the steady steps, FCSE is expected to become a leading, high impact, international scientific journal in the near future. In pursuing the goals of FCSE we need a robust partnership with authors, reviewers, governance, and staffs.

\section{References}

1. Bell I H, Wronski J, Quoilin S, Lemort V. Pure and pseudo-pure fluid thermophysical property evaluation and the open-source thermophysical 
property library CoolProp. Industrial \& Engineering Chemistry Research, 2014, 53(6): 2498-2508

2. Cakici M, Reddy K R, Alonso-Marroquin F. Advanced electrochemical energy storage supercapacitors based on the flexible carbon fiber fabriccoated with uniform coral-like $\mathrm{MnO}_{2}$ structured electrodes. Chemical Engineering Journal, 2017, 309: 151-158

3. Yu S J, Wang X X, Pang H W, Zhang R, Song W C, Fu D, Hayat T, Wang X K. Boron nitride-based materials for the removal of pollutants from aqueous solutions: A review. Chemical Engineering Journal, 2018, 333: 343-360

4. Wang W, Gong J L. Methanation of carbon dioxide: An overview. Frontiers of Chemical Science and Engineering, 2011, 5(1): 2-10

5. Mumford K A, Wu Y, Smith K H, Stevens G W. Review of solvent based carbon-dioxide capture technologies. Frontiers of Chemical Science and Engineering, 2015, 9(2): 125-141

6. Special Topic on environment and sustainable development. Frontiers of Chemical Science and Engineering, 2017, 11(3): 291-292

7. Crittenden J C, Elimelech M, Li D, Lu Z M. Key findings of the 2016 symposium on the frontiers of chemical science and engineering: Environment and sustainable development. Frontiers of Chemical Science and Engineering, 2017, 11(3): 305-307

8. Allen D T. Combining innovative science and policy to improve air quality in cities with refining and chemicals manufacturing: The case study of Houston, Texas USA. Frontiers of Chemical Science and Engineering, 2017, 11(3): 293-304

9. Sun Z, Cao H, Venkatesan P, Jin W, Xiao Y, Sietsma J, Yang Y. Electrochemistry during efficient copper recovery from complex electronic waste using ammonia based solutions. Frontiers of Chemical Science and Engineering, 2017, 11(3): 308-316

10. Iacobescu R I, Cappuyns V, Geens T, Kriskova L, Onisei S, Jones P T, Pontikes Y. The influence of curing conditions on the mechanical properties and leaching of inorganic polymers made of fayalitic slag. Frontiers of Chemical Science and Engineering, 2017, 11(3): 317-327

11. Yu L, Miao J, Jin Y, Lin J Y S. A comparative study on polypropylene separators coated with different inorganic materials for lithium-ion batteries. Frontiers of Chemical Science and Engineering, 2017, 11(3): 346-352

12. Ulrich J, Frohberg P. Problems, potentials and future of industrial crystallization. Frontiers of Chemical Science and Engineering, 2013, 7(1): 1-8

13. Zhang W, Szostak J W, Huang Z. Nucleic acid crystallization and X-ray crystallography facilitated by single selenium atom. Frontiers of Chemical Science and Engineering, 2016, 10(2): 196-202

14. Huang Z, Lilley D M J. Preface. Frontiers of Chemical Science and Engineering, 2016, 10(2): 177

15. Wilson T J, Liu Y J, Lilley D M J. Ribozyme and the mechanisms that underlie RNA catalysis. Frontiers of Chemical Science and Engineering, 2016, 10(2): 178-185

16. Brčić J, Plavec J. G-quadruplex formation of oligonucleotides containing ALS and FTD related GGGGCC repeat. Frontiers of Chemical Science and Engineering, 2016, 10(2): 222-237

17. Xie Z X, Li B Z, Mitchell L A, Wu Y, Qi X, Jin Z, Jia B, Wang X, Zeng B X, Liu H M, et al. "Perfect" designer chromosome V and behavior of a ring derivative. Science. 2017, 355(6329): eaaf4704

18. Wu Y, Li B Z, Zhao M, Mitchell L A, Xie Z X, Lin Q H, Wang X, Xiao W H, Wang Y, Zhou X, et al. Bug mapping and fitness testing of chemically synthesized chromosome X. Science. 2017, 355(6329): eaaf4706

19. Yuan Y J, Wu J C, Wang X. Collaborations of China with the world in Synbio. Frontiers of Chemical Science and Engineering, 2017, 11(1): 1-2

20. Wang Q Z, Tang S Y, Yang S. Genetic biosensors for small-molecule products: Design and applications in high-throughput screening. Frontiers of Chemical Science and Engineering, 2017, 11(1): 15-26

21. Wan H, Xia Y, Li J H, Kang Z, Zhou J W. Identification of transporter proteins for PQQ-secretion pathways by transcriptomics and proteomics analysis in Gluconobacter oxydans WSH-003. Frontiers of Chemical Science and Engineering, 2017, 11(1): 72-88

22. Wang R Z, Gu X L, Yao M D, Pan C H, Liu H, Xiao W H, Wang Y, Yuan Y J. Engineering of beta-carotene hydroxylase and ketolase for astaxanthin overproduction in Saccharomyces cerevisiae. Frontiers of Chemical Science and Engineering, 2017, 11(1): 89-99

23. Wang S J, Ma Z H, Zhang T, Bao M D, Su H J. Optimization and modeling of biohydrogen production by mixed bacterial cultures from raw cassava starch. Frontiers of Chemical Science and Engineering, 2017, 11(1): 100-106

24. Yuan T, Guo Y K, Dong J K, Li T Y, Zhou T, Sun K W, Zhang M, Wu Q Y, Xie Z, Cai Y Z, Cao L M, Dai J B. Construction, characterization and application of a genome-wide promoter library in Saccharomyces cerevisiae. Frontiers of Chemical Science and Engineering, 2017, 11(1): 107116

25. Ye L D, Lv X M, Yu H W. Assembly of biosynthetic pathways in Saccharomyces cerevisiae using a marker recyclable integrative plasmid toolbox. Frontiers of Chemical Science and Engineering, 2017, 11(1): 126-132

26. Mccue A J, Anderson J A. Recent advances in selective acetylene hydrogenation using palladium containing catalysts. Frontiers of Chemical Science and Engineering, 2015, 9(2): 142-153

27. Zhu J, Meng X J, Xiao F S. Mesoporous zeolites as efficient catalysts for oil refining and natural gas conversion. Frontiers of Chemical Science and Engineering, 2013, 7(2): 233-248

28. Wan S L, Wang Y. A review on ex situ catalytic fast pyrolysis of biomass. Frontiers of Chemical Science and Engineering, 2014, 8(3): 280-294

29. Liu Z M, Li J Z. Frontiers of catalysis chemistry and technology. Frontiers of Chemical Science and Engineering, 2018, 12(1): 1-2

30. Portela R, Perez-Ferreras S, Serrano-Lotina A, Bañares M A. Engineering operando methodology: Understanding catalysis in time and space. Frontiers of Chemical Science and Engineering, 2018, 12(3): 509-536

31. Zhang T, Asefa T. Copper nanoparticles/polyaniline-derived mesoporous carbon electrocatalysts for hydrazine oxidation. Frontiers of Chemical Science and Engineering, 2018, 12(3): 329-338

32. Qian F. Smart and optimal manufacturing: The key for the transformation and development of the process industry. Engineering, 2017, 3(2): 151 
33. Yue W C, Chen X F, Gui W H, Xie Y F, Zhang H L. Performance monitoring of non-gaussian chemical processes with modes-switching using globality-locality preserving projection. Frontiers of Chemical Science and Engineering, 2017, 11(3): 414-428

34. Peng X, Tang Y, Du W L, Qian F. Molecular dynamics study of water diffusion in an amphiphilic block copolymer with large difference in the blocks' glass transition temperatures. Frontiers of Chemical Science and Engineering, 2017, 11(1): 429-439 